\title{
LOS ORÍGENES DEL DERECHO GENERAL ARAGONÉS: DEL FUERO DE JACA A LOS FUEROS DE ARAGÓN DE 1247
}

\author{
THE ORIGINS OF THE ARAGONESE GENERAL LAW: \\ FROM THE FUERO DE JACA TO THE FUEROS DE ARAGÓN OF 1247
}

\author{
Vicent GARCÍA EDO \\ Universitat Jaume I
}

Resumen: En este artículo estudiamos tanto las fuentes documentales como el proceso de redacción de los Fueros de Aragón promulgados por el rey Jaime I en 1247 , que constituyen la base del derecho general aragonés. Establecemos una clara distinción entre los Fueros y el Vidal Mayor, una obra de mera literatura jurídica con la que se les suele confundir. También analizamos las adiciones a dichos Fueros hechas durante el resto del reinado de este monarca, así como otras realizadas a mediados del siglo XV, que por el hecho de figurar ya incluidas en la primera edición incunable de 1476-77 de los Fueros, se las ha considerado siempre y sin razón como parte del texto primitivo.

Palabras clave: orígenes del derecho aragonés, legislación de Jaime I, fueros de Aragón de 1247, Vidal Mayor, reino de Aragón, siglo XIII.
Abstract: In this article we study both the documentary sources and the drafting process of the Fueros de Aragón promulgated by king Jaime I in 1247, which constitute the basis of Aragonese general law. We establish a clear distinction between the Fueros and the Vidal Mayor, a work of mere legal literature with which they are often confused. We also analyze the additions to these Fueros made during the rest of the reign of this monarch, as well as others made in the mid-fifteenth century, which because of the fact already included in the first incunable edition of 1476-77 of the Fueros, are he has always mistakenly considered part of the primitive text.

Key words: Origins of the Aragonese law, Legislation of Jaime I, Fueros de Aragón of 1247, Vidal Mayor, kingdom of Aragon, $13^{\text {th }}$ Century 


\section{Introducción}

El Fuero latino extenso de Jaca ${ }^{1}$ se comenzó a redactar durante el reinado de Sancho Ramírez (1064-1094), con la intención de aplicarlo solo en dicha ciudad desde el momento mismo en que se convirtió en la primera capital del reino de Aragón. No obstante, hay indicios más que razonables que permiten creer que también se utilizó, muy a finales del siglo XI, para confeccionar el Fuero latino extenso de Huesca, cuando después de su conquista pasó a convertirse en la nueva capital del reino; si bien no es posible establecer por el momento la verdadera dimensión del primitivo fuero oscense. A partir de 1119 , recién conquistada Zaragoza y convertida en la tercera y definitiva capital de Aragón, se redactó un nuevo fuero, también en latín, del cual hemos conservado una gran parte del articulado, lo que permite saber que también deriva directamente del citado Fuero de Jaca.

El Fuero de Zaragoza ${ }^{2}$ se extendió a numerosas poblaciones del Valle del Ebro y otras zonas más o menos próximas, a través de cartas de población en las que se autorizaba su uso. Entre todas estas localidades destacan Borja y Tarazona que, por su importancia, no se limitaron a tener solo reconocido de forma genérica el Fuero de Zaragoza, sino que en cada una de ellas se preocuparon por generar un derecho local con nombre propio.

Sin embargo, no en todos los casos se procedió del mismo modo. Conforme avanzó la conquista cristiana por gran parte del centro y sur de Aragón, coincidiendo con el territorio de las cuatro grandes comunidades de villas y aldeas de Calatayud, Daroca, Teruel y Albarracín, en cada una de ellas se promulgaron fueros de naturaleza y contenido diverso que nada tenían que ver con los anteriores y, salvo en contadas excepciones, no se expandieron más

1 La existencia y características del mismo ha sido objeto de reciente publicación en esta revista: García Edo, 2017: 39-66.

2 El Fuero de Zaragoza figura citado en numerosas ocasiones en la documentación de los siglos XII y XIII, pero es muy poco conocido por los historiadores. Todavía sin una correcta identificación, un manuscrito parcial del mismo fue publicado hace casi un siglo: Ramos Loscertales, 1925: 491-523. Este autor escribió únicamente al respecto que se trataba de una recopilación adaptada por un jurisconsulto, posiblemente del primer tercio del siglo XIII y de Zaragoza, para ser usada en la comarca aragonesa de riberas del Ebro. Una segunda edición del mismo manuscrito, en la que no se analizaba su contenido en el breve comentario introductorio a la misma, lo definió bastante mejor, como Fuero de Borja y Zaragoza, en Morales Gómez y Pedraza García, 1986. Más recientemente se ha llevado a cabo un primer estudio de conjunto sobre este fuero. García Edo, 2016: 165-197. Sobre la importancia del Fuero de Zaragoza a lo largo del tiempo, es especialmente destacable el estudio de $\mathrm{M}^{\mathrm{a}}$ Luisa Ledesma Rubio, 1992: 63-78. 
allá de los términos generales de sus respectivas comunidades. Y tampoco parece que tuvieran influencia alguna a mediados del siglo XIII cuando, por mandato del rey Jaime I se convocaron las Cortes de Huesca de 1247, con el fin de aprobar y promulgar el primer gran cuerpo legal de Fueros de Aragón, redactado en latín por los juristas de la Cancillería Real, en su mayor parte a partir de los fueros municipales de Jaca, Huesca, y Zaragoza. Esta elección no debe sorprendernos puesto que dichos textos presentaban un contenido muy homogéneo, al proceder de una fuente común, y durante más de un siglo habían demostrado su eficacia en buena parte del reino de Aragón.

La redacción de los Fueros de 1247, de los que se conserva un importante número de copias medievales manuscritas, tanto de la versión oficial y original latina ${ }^{3}$ como de las traducciones en romance ${ }^{4}$ realizadas en los siglos XIV y XV, ha despertado en muchas ocasiones el interés de los historiadores. Por ello existe una abundante bibliografía al respecto, sobre la que no podemos ocuparnos en este artículo por razones de espacio, con importantes aportaciones sobre la cuestión en la mayor parte de los casos, si bien en otros hay confusiones y errores de interpretación relativos a la autoría de la obra, la negación de que el latín fuera la lengua de redacción original, la discusión sobre el número inicial de libros o partes en que se dividió el texto original latino $\mathrm{y}$, sobre todo, la falsa creencia de la existencia de una versión breve, o Compilatio Minor de dichos Fueros, que fue la promulgada por Jaime I en dichas Cortes, y una versión extensa, o Compilatio Maior, que se identifica con el texto del Vidal Mayor, obra redactada por el jurista y obispo de Huesca, Vidal de Canellas, a instancias del rey, inmediatamente después de que se promulgaran los Fueros, con el fin de que los juristas dispusieran de una obra complementaria, sin valor legal pero sí consultivo, explicativa o aclaratoria del

3 Pérez Martín, 2010. El autor realiza un gran trabajo de conjunto, basado en el análisis y comparación de los once manuscritos conocidos de los siglos XIV y XV que contienen la versión oficial de los Fueros de Aragón de 1247.

4 Pérez Martín, 1999. En este libro publicó el breve fragmento de la traducción en romance occitano del texto de los Fueros, realizada a finales del siglo XIII o comienzos del XIV, así como el de cada uno de los cuatro manuscritos conocidos escritos en romance aragonés, de los siglos XIV y XV, dispuestos en sendas columnas en paralelo, lo que permite comprobar con gran facilidad las enormes diferencias que hay entre ellos, tanto en extensión como en contenido, pues se trataba de traducciones realizadas por iniciativa privada, en épocas diferentes y con criterios distintos, razón por la cual carecían de valor legal. Esta circunstancia, por tanto, las convierte en piezas secundarias a la hora de estudiar la gestación de los Fueros de Aragón de 1247, criterio que ya hemos seguido en este artículo en el que las menciones a las mismas son prácticamente nulas, pues han tenido hasta ahora una consideración que no les correspondía y, debido a ello, han causado importantes errores históricos que será muy difícil desterrar. 
contenido de los aproximadamente 336 artículos de que constaba el nuevo texto legal, ${ }^{5}$ y en la que al mismo tiempo se añadieron otros muchos textos que, sin ser propiamente comentarios a esas leyes, fueran de ayuda para la comprensión del significado de otras instituciones jurídicas vigentes en la época, no citadas expresamente en los Fueros de 1247.

En las páginas que siguen, trataremos de hacer una reconstrucción razonada de la forma en que se llevó a cabo el largo proceso al que acabamos de referirnos, aportando las pruebas necesarias que demuestran que los orígenes del derecho aragonés pueden explicarse de una manera bastante más sencilla de lo que acostumbramos, parecida a la de otros reinos medievales peninsulares, gracias a la existencia suficiente de documentos que, si son estudiados e interpretados en su justa medida proporcionan, si no todas, al menos la mayor parte de las claves necesarias para comprender mejor el largo proceso iniciado en Jaca en la segunda mitad del siglo XI y completado en Huesca en los primeros días de enero de 1247, cuando el rey Jaime I promulgó el primer cuerpo legal extenso de aplicación en todo el reino de Aragón.

\section{El Fuero latino extenso de Jaca}

A comienzos de su reinado, Sancho Ramírez (1064-1094) concedió a los hombres de Jaca un importante privilegio, que podemos considerar la primera manifestación escrita de un derecho propio de la ciudad, si bien el documento que lo acreditaba no ha llegado a nuestros días, aunque su existencia puede deducirse de la lectura de un privilegio posterior, promulgado en 1134, durante el reinado de Ramiro II, en el que se transcribe y confirma el contenido del manuscrito perdido que, al menos, constaba de dieciséis artículos; los mismos que figuran en un segundo privilegio ${ }^{6}$ que los historiadores convienen en situar en el año 1077, cuando Sancho Ramírez concedió a Jaca el título de ciudad, y aprovechó la ocasión para añadir ocho disposiciones nuevas, con lo

5 Hemos reunido copia de todos los manuscritos latinos conocidos de los siglos XIV y XV de los Fueros de Aragón de 1247 y, tras su comparación directa, puede afirmarse que el de la catedral de Tortosa (códice 248, ff. 3r-48r) transmite el más antiguo estado del texto llegado a nuestros días, no sólo por las enormes diferencias con las versiones últimas del mismo, sino también por incluir las adiciones realizadas durante el resto del reinado de Jaime I, cosa que no encontramos de manera tan precisa en los demás manuscritos; y ello nos permite conocer la extensión real del texto foral en el momento de su promulgación.

6 Archivo Municipal de Jaca. Pergamino ${ }^{\circ}{ }^{1}$. Copia simple del siglo XII. 
cual este segundo privilegio, escrito en latín y llegado a nuestros días a través de una copia del siglo XII, consta de un total de veinticuatro artículos y, a falta del primero, suele ser erróneamente considerado como el texto más antiguo de derecho municipal jacetano, ${ }^{7}$ y se le conoce habitualmente como «el Fuero de Jaca»; ello origina una nueva confusión pues, un texto de tan corta extensión y contenido no parece que pueda ser considerado sino como una carta puebla, o un mero privilegio, sin tan siquiera llegar a alcanzar la categoría de fuero municipal breve si lo comparamos con otros textos similares del siglo XI. Confusión que al mismo tiempo ha restado protagonismo a la existencia del verdadero Fuero de Jaca, que es la versión latina extensa que, con ese nombre, se desarrolló tras la erección de Jaca en ciudad.

Así pues, tan pocas normas e independientemente de su enorme importancia, no eran bastantes para atender las necesidades que en sus primeros momentos tenía la ciudad de Jaca en materia jurídica, aunque es más que probable que los juristas que trabajaran en aquellos momentos al servicio del todavía incipiente concejo municipal, con la denominación que tuviese, o aquellos otros que estuvieran ejerciendo su oficio al servicio de la corona, en una no menos incipiente pero imprescindible oficina precedente de la futura cancillería real, estuvieran empleando algún derecho anterior de origen hispánico, o transpirenaico, a tenor de la procedencia de muchos de los hombres, de la condición social que fuera, que acudieron en apoyo del rey de Aragón y en busca de fortuna, participando en las campañas militares de conquista de tierras aragonesas a los musulmanes. Razón por la cual no nos cabe duda de que muy poco después de la promulgación de estos dos privilegios, unos y otros propiciasen la redacción de un derecho complementario del concedido hasta esos momentos - necesario para la ciudad en cualquiera de sus facetas, especialmente en materia civil, penal y procesal-, y dedicasen también una atención especial al estatuto de los infanzones, una clase social muy singular, que tuvo un papel verdaderamente notable desde los orígenes del reino, y así se les reconoció en el articulado de ese nuevo derecho, o Fuero latino extenso de Jaca.

En las últimas décadas del siglo XI cualquier texto, de la naturaleza que fuese, estaba siempre escrito en latín. Era la lengua de la cultura y, por tanto,

7 Las especiales características del segundo privilegio (1077) de Sancho Ramírez a los hombres de Jaca, ya fue advertida bastante tiempo: Barrero, 2004: 113-160 (la cita expresa en p. 125). Existe una publicación más reciente, que trata de las características de los dos privilegios otorgados a Jaca por Sancho Ramírez: García Edo, 2017: 39-63 (las referencias concretas en pp. 44-48). 
también la del derecho, lo que significa que es la que se empleaba no solo para la redacción de cualquier nuevo texto legislativo, sino también para la totalidad de documentos de aplicación del derecho. ${ }^{8} \mathrm{Y}$ en esa lengua fue en la que escribieron el Fuero latino extenso de Jaca los anónimos juristas responsables de su lenta elaboración, pues fue resultado de muchos años de trabajo, así como de mejoras y ampliaciones realizadas a lo largo de más de un siglo, como se desprende de la documentación conocida actualmente, lamentablemente no tanta como sería de desear. ${ }^{9}$

Hasta hace muy poco tiempo conocíamos el texto completo del Fuero extenso de Jaca, pero solo en romance occitano, a través de una traducción efectuada en el paso del siglo XIII al XIV y conservada en dos manuscritos, uno de esta última centuria citada. Desde su publicación (Molho, 1964: 15-162) fue considerado por muchos historiadores y sin más prueba que la de su mera existencia, como la versión original del texto, algo imposible por las razones que acabamos de señalar.

Muy recientemente, sin embargo, se ha podido demostrar (García Edo, 2017: 39-66) que un par de textos jurídicos latinos existentes en un códice ${ }^{10}$ misceláneo del siglo XIII — que recoge también documentación más antiguapublicados hace casi un siglo, ${ }^{11}$ son en realidad dos importantes fragmentos del Fuero latino extenso de Jaca y que en conjunto constituyen unas dos terce-

8 A fecha de hoy, el primer documento original aragonés que conocemos, de naturaleza jurídica y escrito solo parcialmente en romance, es un breve texto fechado en enero de 1168, mediante el cual Lope, hijo de María Tarés, hace donación de sus bienes al monasterio de Veruela. Constituye una rara excepción, también en la documentación de dicho monasterio, en donde han de pasar muchos años hasta encontrar otros documentos en lengua romance. Archivo Histórico Nacional (AHN), Clero. Pergaminos de Veruela, carpeta $3763, \mathrm{n}^{\circ} 9$.

9 Es muy importante a este respecto la propuesta de una «cronología de las diez partes del básico Fuero de Jaca» (Ubieto, 1989: 37-39), aunque desde nuestro punto de vista es difícilmente defendible, porque parte de la base de una redacción por bloques que, probablemente, en parte se dio, pero no contempla el hecho de que el conjunto del texto estuvo en permanente revisión a lo largo del siglo XII y, por tanto, como no conocemos sino dos fragmentos de una de las redacciones más antiguas, de los que no sabemos si pertenecían a la misma, por el momento es tarea imposible seguir avanzando en una propuesta de esa naturaleza.

10 Biblioteca Universitaria de Zaragoza, manuscrito 225, conocido como Códice Villarense.

11 Fueron publicados hace casi un siglo, aunque considerados como unas simples recopilaciones de derecho aragonés muy vinculadas al derecho municipal de Jaca. Ramos Loscertales, 1925: 491-523 (segundo fragmento) y Ramos Loscertales, 1928: 389-411 (primer fragmento). Numerosos autores citan la existencia de estos textos, si bien no los valoraron en su justa medida, sino que los consideraron mero complemento de la versión romance completa del Fuero extenso de Jaca. Incluso en una conocida publicación (Ubieto, 1991: 34-37), figura una tabla comparativa entre varios manuscritos del fuero romance y esta versión latina, pero sin merecer comentario alguno sobre su carácter prototípico. 
ras partes de los 287 artículos de que constaba el texto a finales del siglo XII y comienzos del XIII. A partir de su análisis podemos señalar que, en líneas generales, se trata de un primer bloque de 59 artículos, que se corresponde de modo incompleto con los artículos 1-61 (y algunos posteriores) de la versión romance del texto; y un segundo bloque de 155 artículos, que se corresponde también de manera incompleta con los artículos 170 a 287 de esa misma versión romance. Como en el encabezamiento de este segundo opúsculo se dice que daba comienzo un libro, podemos suponer que en origen el Fuero latino extenso de Jaca constaba de dos libros o partes, de los que afortunadamente nos quedan estos dos amplios fragmentos $y$, aunque el resto a fecha de hoy no se conoce, desde el punto de vista del contenido esa falta la compensa la existencia de la traducción romance antes citada.

No es preciso que nos detengamos ahora en glosar el éxito que tuvo el texto del Fuero latino extenso de Jaca desde sus orígenes, pues muy pronto comenzó a expandirse dentro y fuera de Aragón, especialmente en Navarra. El rey Sancho Ramírez ya lo concedió a la villa de Sangüesa y, andando el tiempo, Alfonso I de Aragón se lo confirmó en 1117. Un año antes había comenzado a ejercer como justicia real don Pedro Jiménez (act. 1116-1129), fundador de la Casa de Urrea, quien debió tener algún protagonismo en esta iniciativa desde tan alto oficio, como también debió tenerlo a partir de 1119 para aplicarlo en Zaragoza, tras su conquista, en donde al menos desde 1124 ya empieza a citarse en la documentación ordinaria de las escribanías públicas con la denominación forum Cesarauguste. También fue durante el reinado de Alfonso I cuando el Fuero de Jaca se implantó en Alquézar (1124) y Aínsa (1125), lo cual podría tener un significado mucho mayor del que unas simples donaciones de esta naturaleza aparentan a primera vista, pues son fechas muy tempranas y esa importación del derecho municipal jacetano vendría a significar que los habitantes de las tierras del Somontano y Sobrarbe carecían de un derecho propio y suficiente para atender sus necesidades en materia jurídica, lo cual es un asunto muy importante a considerar dentro de cualquier estudio de conjunto relativo a los orígenes del derecho aragonés.

\section{El Fuero latino extenso de Huesca}

Poco tiempo duró la capitalidad de Jaca, pues por todos era conocido que ese título pasaría a ostentarlo la ciudad de Huesca cuando se conquistase a los musulmanes, hecho que sucedió en noviembre de 1096 durante el reinado de 
Pedro I de Aragón. No es sino hasta el mes de agosto de 1100 cuando encontramos el documento más antiguo llegado a nuestros días, que algunos califican como la carta fundacional de la ciudad: ${ }^{12}$ un privilegio del rey Pedro I de Aragón que concede carta de ingenuidad a los pobladores de Huesca presentes y futuros, y con ella les exime del pago de lezda y otros censos, exigiendo a cambio fidelidad hacia su persona y las de sus descendientes. No podemos dudar de la importancia de este privilegio pero no cita ni sugiere cuál sea o haya de ser el régimen jurídico extenso de la ciudad, necesario para regular las relaciones diarias de sus habitantes, y que sin duda ya debía existir, tal como había sucedido décadas atrás en Jaca, al convertirse en capital del reino de Aragón.

Hemos avanzado bastante en ese sentido en los últimos años, hasta el punto de poder proponer para Huesca un itinerario similar al realizado en Jaca a la hora de redactar su fuero extenso, si bien con un matiz, pues existiendo un texto legislativo de cierta consideración y prestigio en la que hasta esos momentos era la capital del reino, no parece que hubiera demasiada necesidad de generar un derecho totalmente distinto en la ciudad de Huesca, sino aprovechar el existente, aunque sí fue preciso redactar el articulado complementario necesario para atender a las necesidades propias de la nueva capital del reino, no contempladas hasta ese momento por el derecho jacetano.

Actualmente se sigue considerando ejemplo de ese primer derecho extenso oscense, el contenido de dos manuscritos (Ubieto, 1991: 29-30), a cuya mención nos limitaremos, pues no alteran el discurso de estas páginas y, en cambio, necesitan ser mejor estudiados, para poder determinar en la medida de lo posible qué son en realidad. El primer manuscrito se corresponde con el citado fragmento inicial del Fuero latino extenso de Jaca, y el motivo de traerlo a colación radica en el hecho de que en dos de sus artículos figura cambiado el nombre de Jaca por el de Huesca, ${ }^{13}$ lo que demuestra que el original fue reutilizado con ese propósito, si bien no sabemos cómo evolucionó con el paso del tiempo.

12 Archivo Municipal de Huesca. Concejo. Traslado de 1301. Signatura V.15. La edición impresa más reciente del breve texto de este importante pergamino es de Laliena, 1988: 13-14.

13 Las dos citas son muy interesantes y constituyen el principal argumento para vincular también el manuscrito al derecho municipal oscense. En el sexto artículo se regula el procedimiento a seguir en caso de homicidio infra terminos Osce y en el noveno se establece que si alguien puede demostrar que posee una heredad por un plazo superior a un año y un día, no está obligado a responder a reclamaciones de terceros por ese motivo, pues así lo dispone el fuerum de Oscha. 
A esa pregunta se podría responder, seguramente, con el análisis del segundo manuscrito, que aparenta ser la versión completa de un original perdido, llegada a nosotros en traducción romance. Consta de 263 artículos, y lo primero que hay que decir de él es que se trata de un texto derivado del Fuero extenso latino de Jaca, con el que coincide en un número importante de artículos pero no en todos, como queda en evidencia a través de la única edición existente (Molho, 1964: 201-274). Su identificación como versión romance del Fuero extenso de Huesca también es razonable (Ubieto, 1991: 30), en especial a partir del contenido del artículo 110 del texto, que parece una disposición real, ordenando que el justicia y a los prohombres de Huesca tengan una participación activa en el nombramiento de los escribanos públicos de la ciudad, con el fin de garantizar que sean buenos profesionales y no incurran en delitos de falsedad.

\section{El Fuero extenso latino de Zaragoza}

A mediados de diciembre de 1118 el rey Alfonso I de Aragón consiguió materializar la que sin duda fue la más grande de sus hazañas, la conquista de Zaragoza a los musulmanes. La ocupación de la ciudad marcó el punto y final de un sueño pero, al mismo tiempo, significó una enorme responsabilidad pues había que comenzar a repartir casas y tierras entre quienes con esa intención participaron de la campaña militar y había que instalarlos y dar leyes que sirvieran para marcar no solo sus relaciones con la corona sino también entre ellos mismos.

Ese derecho no tardó en hacerse patente: la primera manifestación escrita la encontramos en un documento ${ }^{14}$ fechado en el mes de enero de 1119 , en virtud del cual el rey Alfonso concedía vobis, totos populatores de Çaragoza qui ibi estis vel in antea ibi veneritis populare, unos buenos fueros que ya disfrutaban en ese momento los infanzones de Aragón. Esto no significaba concederles con carácter general todo el conjunto de normas escritas que, de manera genérica, pudieran caracterizar en ese momento a los infanzones aragoneses -y que en aquel momento ya eran muy numerosas - , sino únicamente dos o tres, según hagamos el cómputo al leer el texto. Con lo cual, es fácil entender que no son leyes suficientes para poder marcar la vida de los primeros habitantes de Zara-

14 Archivo Municipal de Zaragoza. Privilegios reales. Signatura: R-27. Copia autorizada inserta en otro privilegio de 19 de agosto de 1284. (Canellas, 1972: 83-84) 
goza quienes, sin duda alguna y desde el momento mismo en que la ciudad comenzó a tener una cierta estructura administrativa, apenas unas semanas después de su conquista, necesitaría un texto legislativo lo más extenso y completo posible, para su buen gobierno y el de sus habitantes.

Nos estamos refiriendo a lo que con carácter genérico denominamos Fuero latino extenso de Zaragoza (García Edo, 2015), un texto legal que está documentado a partir del año 1124, y del que además ahora ya conocemos con bastante aproximación el aspecto que mostraba en la primera mitad del siglo XII, lo que permite suponer, como también veremos en estas páginas, que debió comenzar a utilizarse muy poco después de la concesión de enero de 1119 a la que nos acabamos de referir.

Efectivamente, a través de los extensos fragmentos latinos conocidos actualmente del contenido del Fuero de Zaragoza en la primera mitad del siglo XII, podemos comprobar que fue igualmente resultado de la adopción como fuero propio del Fuero latino extenso de Jaca, en vigor por aquellas fechas desde finales del siglo XI, que los juristas de la Cancillería del rey Alfonso I y los de la ciudad de Zaragoza adaptaron a las necesidades que pudieran tener. Esta adaptación se llevó a cabo conservando el articulado jacetano que resultaba de utilidad y añadiendo un número indeterminado de fueros nuevos procedentes de otras fuentes documentales conocidas, como el Fuero de Huesca, aparte de los que redactaron ex profeso de acuerdo con las características de la nueva capital del reino de Aragón.

El nuevo Fuero de Zaragoza surtió los efectos esperados, pues la sociedad a la que iba destinado no era muy distinta, aunque sí más numerosa, que la de la ciudad de Jaca en donde se gestó, de manera que no solo se mantuvo, mejoró y amplió a lo largo del siglo XII y comienzos del XIII, sino que también se aplicó a un destacable número de poblaciones aragonesas, algunas tan importantes como Borja o Tarazona, e incluso se exportó a partir de 1232 a tierras valencianas, en los inicios de la conquista del reino a los musulmanes, aplicándose a través de las respectivas cartas de población a un buen número de poblaciones de sus comarcas más septentrionales.

\section{Los Fueros de Aragón de 1247}

No hay duda alguna de que la principal manifestación del derecho histórico aragonés la constituye el cuerpo general de sus Fueros, promulgados en asam- 
bleas de Cortes celebradas entre finales del siglo XII y comienzos del XVIII. De todos ellos los historiadores se han interesado especialmente por el estudio de los correspondientes a las Cortes de Huesca de 1246-47, porque dieron lugar a la implantación de un texto legislativo extenso para el conjunto del reino, cerrando de ese modo un largo periodo de tiempo en el que el derecho aragonés no fue sino la suma de un amplio mosaico de derechos locales, distintos los unos de los otros, con las consecuencias que tal circunstancia pudiera provocar.

Los Fueros de Aragón de 1247 también se redactaron en latín y esa fue, además, su versión oficial hasta el fin de la época foral. A falta de los manuscritos originales, actualmente conocemos once copias de los siglos XIV y XV, todas ellas muy homogéneas aunque contengan numerosas variantes propias de este tipo de manuscritos, más de forma que de fondo, al estar realizadas por distintos escribanos. Entre las variantes destacan los cambios de posición de algunos de sus artículos, a veces por olvido, que se salvan habitualmente colocándolos en otro punto cualquiera del manuscrito; aunque en ocasiones el cambio de lugar deriva del criterio del jurista, o del comitente, al considerar que en una nueva posición encajan mejor por razón de la materia tratada.

Desde finales del siglo XIII o principios del XIV comenzaron a realizarse las primeras traducciones de la versión latina de los fueros aragoneses a lenguas romance, con el fin de facilitar su acceso a sectores sociales algo más amplios. Actualmente se conocen cuatro manuscritos escritos en castellano-aragonés y el fragmento de un quinto, el más antiguo de todos, escrito en lengua occitana. No tuvieron carácter oficial ni transmiten un mismo texto, sino que se trataba de iniciativas privadas para uso de juristas que, en algún caso, seguían con mayor o menor fidelidad la versión latina aunque a veces incluyeron extensos pasajes de otras procedencias, razón por la cual no constituyen la mejor vía para tener un conocimiento real de la primera compilación de Fueros de Aragón, ni son recomendables para los historiadores en general, a la hora de llevar a cabo según qué tipo de estudios quieran realizarse, por las confusiones a que pueden dar lugar.

Frente a tan alto número de manuscritos, no conservamos documentación complementaria de la Cancillería de Jaime I que pudiera arrojar alguna luz sobre la manera en que se gestó la redacción de este nuevo texto legislativo. Por esta razón solamente podemos intentar aproximarnos a los hechos por vías indirectas, en especial a través del propio prólogo del texto, lo que produce unos resultados bastante pobres, aunque a fecha de hoy son los únicos fiables, 
por estar contenidos en un texto de caràcter legal. Y, a pesar de que el prólogo no es una ley por sí misma, no es menos cierto que tanto en este como en otros muchos textos de naturaleza similar se aprovecha la introducción para justificar su redacción, de forma más o menos extensa.

Tenemos la convicción de que los Fueros de 1247 debían estar ya redactados antes de la apertura de las sesiones de las Cortes de Huesca presididas por el rey Jaime I, ya que no es posible que en el siglo XIII se compusiera, debatiera y promulgara un texto que consta de alrededor de 336 artículos, que deriva y mezcla contenidos de fuentes documentales muy diversas; teniendo igualmente en cuenta que la presencia de Jaime I en Huesca es posterior al 18 de diciembre de 1246, y el 6 de enero de 1247 los Fueros ya estaban promulgados. Como mucho, se puede presumir que en dichas sesiones se debatiría sobre puntos muy concretos, aunque también esto parece improbable por la estricta fidelidad de la mayor parte del articulado a las fuentes documentales de derecho aragonés que utilizaron los legisladores responsables de su elaboración. Éstos no pudieron ser otros sino los juristas de la Cancillería Real quienes, por mandato del rey, debieron establecer contactos con representantes legales de los brazos de las Cortes, en especial de la nobleza y las ciudades y villas, lo que les permitiría conocer su punto de vista y exigencias, así como reunir un conjunto variado de fuentes legales caso que no las tuvieran, casi todas aragonesas, a partir de las cuales se llevó a cabo la redacción del borrador de los nuevos fueros aragoneses.

Ello no significa que el resultado fuera del agrado de los juristas de la Cancillería ni del propio monarca, porque a lo largo del proceso de redacción del texto quedaron patentes las exigencias de los brazos de las Cortes, deseosos de mantener el derecho tradicional aragonés vigente. La corona, en cambio, preferiría introducir en Aragón los principios del ius commune, la nueva corriente de pensamiento jurídico procedente de Italia, basada en el antiguo derecho romano-justinianeo, mucho más amplio y rico que cualquier otro derecho en vigor en esos momentos por tierras europeas, y que los reyes deseaban implantar en sus reinos, puesto que era muy útil para reforzar a la institución monárquica.

La firmeza de los aragoneses, manifestada en muchas otras ocasiones, también se mantuvo esta vez, de tal manera que con disputas con el rey, o sin ellas, no accedieron a rebajar sus deseos de mantener su derecho foral, por lo que el texto de los Fueros de Aragón de 1247 está redactado únicamente a partir de fuentes documentales reconocidas y aceptadas por ellos; y el monarca no tuvo 
más remedio que promulgar el texto legislativo resultante de los trabajos realizados por los juristas de la Cancillería, quienes trataron de darle un orden que recordara el esquema del Codex justinianeo, tarea verdaderamente imposible dadas las características de cada texto.

\subsection{El escenario de la iniciativa legislativa}

En el año 1245 y tras la toma del castillo de Biar, el rey Jaime I dio por acabada la campaña militar de conquista del reino de Valencia, poniendo fin a doce años de guerra con los musulmanes e inaugurando, aunque por no demasiado tiempo, un insólito periodo de paz que quiso aprovechar para llevar a cabo importantes iniciativas, tanto de carácter político como jurídico, entre las que destacó su deseo de dotar de un derecho territorial extenso al reino de Aragón, el más antiguo de los estados que integraban su corona..$^{15}$ Así se desprende de la lectura del prólogo latino de los Fueros de Aragón, testimonio directo y único ${ }^{16}$ de la voluntad del rey.

Traemos aquí algunos pasajes de la versión en romance occitano del texto, poco conocido y al parecer la más fiel al original latino (Martínez Díez, 1980:

15 Se daba la paradoja de que siendo el reino más antiguo, todavía no tenía un derecho territorial, mientras que a consecuencia de las campañas militares contra los musulmanes mallorquines y valencianos, en marzo de 1230 ya había concedido un doble derecho local y territorial a Mallorca, materializado en el texto de las Ordinacions de Mallorca, y en octubre-noviembre de 1238 llevó a cabo una iniciativa similar pero mucho más ambiciosa, con la promulgación de la Costum de la ciutat e regne de València. No podía ser que Aragón siguiera careciendo de un derecho territorial propio, para lo cual dedicó el tiempo y los medios necesarios para conseguirlo. En tierras catalanas las cosas eran distintas, y ya llegaría el momento en que pudieran disponer de una legislación territorial similar, lo cual sucedió muy a finales del siglo XIII.

16 Testimonio único porque, si bien es cierto que existen otras versiones de este prólogo en los restantes manuscritos de las traducciones romance de los Fueros de Aragón, estas no son sino recreaciones o interpretaciones libres (excepto el redactado en romance occitano) de un texto latino compuesto muchos años antes, por lo que carecen del valor y el rigor del original compuesto directamente por los promotores de la redacción del texto legislativo. Numerosos historiadores también conceden el mismo valor que al prólogo latino de los Fueros, al prólogo romance de la obra conocida con el nombre de Vidal Mayor, que muchos consideran, erróneamente, una versión o compilación extensa de los citados fueros aragoneses, a la que atribuyen pleno valor legal, cuando no hay prueba alguna de tal circunstancia, si bien es cierto que fue un encargo del rey al jurista y obispo de Huesca, don Vidal de Canellas, tras no haber conseguido que las Cortes de Huesca de 1247 accedieran a incorporar en el articulado de los nuevos Fueros nada que procediera de las fuentes del ius commune de origen italiano, tan completo y tan de moda en aquellos momentos. El deseo del rey se vio de nuevo frustrado, porque las Cortes aragonesas nunca aprobaron esa iniciativa, con lo que el Vidal Mayor, por otra parte una obra excelente de literatura jurídica aragonesa y romana, no pasó de ser sino una obra muy consultada por juristas aragoneses entre la segunda mitad del siglo XIII y las primeras décadas del XVI, por la variedad y riqueza de su contenido. 
69-92 $)^{17}$ que ya se ha publicado en más ocasiones, en donde podemos comprobar la preocupación del rey, en época de paz, por dotar al reino de Aragón de unos fueros conformes al papel y a la importancia del primer reino de su corona:

[...] entendentz proveder al temps de la patz lo nostre entendement als Fueros d'Aragón, per los quals aquel regne es cabo de la nostra alteza [...]

Ello no significaba tener que comenzar de cero, sino que reconocía la existencia de textos forales en vigor, sobre cuya naturaleza no se pronuncia, aunque señala que era necesario modificarlos y mejorarlos en debida forma, para lo cual había decidido convocar a las Cortes de Aragón:

Mas per ço que·ls nostros feytz sían feytz plus sàviament, els Fueros d'Aragón anadén e trahén e exponén e profitosament emendantz, en la ciudad d'Osca general cort mandamos aplegar.

A esas Cortes asistieron el infante don Fernando de Aragón tío del rey, los obispos de Zaragoza y Huesca, los ricoshombres don Pedro Cornel, que era mayordomo de Aragón, don Guillem de Entenza, don García Romeo, don Rodrigo de Lizana, don Jimén de Foces y don Artal de Luna, todos ellos citados expresamente; pero también un número importante de caballeros e infanzones, cuyos nombres no se detallan; así como representantes de distintas ciudades y villas del reino, tampoco nombrados de forma particular. Se señala después que, en presencia de todos ellos, se hicieron leer los Fueros, tal como aparecían en numerosos escritos de sus antepasados:

[...] los Fueros d'Aragón, así como per moltz escriutz de nostres antecessors los trobams, en nostra presencia fazemos legir.

Hecho lo cual, se respetaron todas aquellas cosas que convenía mantener, se eliminaron las superfluas y poco provechosas, se corrigieron las malas redacciones así como los textos oscuros con el fin de dar lugar a interpretaciones más correctas y, finalmente, con todo ello se confeccionó un nuevo volumen manuscrito, ordenado por títulos, al que se trasladaron algunas cosas cambiadas de lugar y se modificaron otras. Todo esto se hizo en presencia de los brazos de las

17 También es la versión romance más antigua conocida, seguramente de finales del siglo XIII o de la primera década del XIV, como lo pone de manifiesto la particularidad gráfica de utilizar «tZ» en lugar de «s», al final de las palabras en plural, algo propio de la documentación del periodo indicado no solo en Aragón, sino también en el resto de territorios de la antigua corona aragonesa. 
Cortes, que también dieron su aprobación, si bien una opinión autorizada considera que estas solo tuvieron un papel deliberativo, ${ }^{18}$ pues el rey no compartió su tarea legisladora con nadie, lo cual es muy probable que fuera cierto:

Todas las cosas dels quals gardadas, e las sobrefluitatz treytas, e las no profitosas cosas complidas, el que no deçía bien, o era escur, por convinentz entrepretacions expost, sotz volumen e certans títols dels anticx fueros algunas cosas moviemos e corregiemos, e la escuritat d'aquels declaramos, lo cosseyl e la esmança de todas las devant ditas personas de tot en tot atorgant.

También se indica que los nuevos Fueros cumplían la doble función de corregir los daños que causaban a la señoría los antiguos, así como la de respetar todas las libertades de los aragoneses adquiridas hasta ese momento:

Per aquestos Fueros en moltas cosas, las quals los anticx fueros ara sens gran dan de las cosas temporals e perigle de las almas, no por çelo de iusticia, mas cobdiciosa maleza, tormentavan a la nostra seynnoría, per aquels alguna cosa no acrexem, ni de las acceptals franqueças dels nostros sotzmessos delivrarán.

Tal como sucede en otros tipos de documentos, de contenido mucho más breve pero idéntico origen, el discurso de los juristas de la Cancellería finalizaba, poniendo en boca del rey, el mandato a todos los oficiales reales, fuesen bayles, justicias, zalmedinas, jurados, jueces, alcaides, junteros o cualesquiera otros, así como al conjunto de los aragoneses, para que a partir de ese momento usasen los nuevos Fueros en todos los actos y todos los pleitos que se originasen en la vida diaria y, en todo cuanto no estuviese contemplado en los mismos, se acudiese al sentido común y a la moderación; declarando que todos aquéllos que los incumpliesen serían debidamente castigados.

Pecaríamos de ingenuos si nos limitásemos a aceptar sin más todo lo anterior, pues los juristas del rey no podían hacer otra cosa sino utilizar un lenguaje diplomático enmarcado dentro de un discurso breve, en donde no se hiciese otra cosa sino prestigiar la figura de Jaime I, presentándolo como un gran legislador, al acometer una iniciativa de tal envergadura, así como persona respetuosa con la tradición foral aragonesa, dejando patente, eso sí, la necesidad de corregir las antiguas leyes en todo aquello que pudiera suponer daño a los propios aragoneses, o a la propia corona en su relación con ellos. 
Sin embargo, el prólogo de los Fueros de Aragón no es más que eso, un texto introductorio. Y aunque contiene interesantes afirmaciones no se dicen todas las verdades, lo que no significa que se mintiese a conciencia, aunque se omitieron datos y acciones que actualmente podemos recuperar parcialmente, gracias a la documentación conservada, a través de cuyo análisis podemos entender mejor el transcurso de los hechos y delimitar mejor el proceso de gestación del nuevo texto foral.

\subsection{Duración de las Cortes de Huesca de 1246-47}

Esta es una cuestión relativamente fácil de responder desde hace bastante tiempo, si bien no ha preocupado a los historiadores, a pesar de ser determinante para comprender que en tan corto periodo de tiempo y, a pesar de lo afirmado en el prólogo de los Fueros al que nos acabamos de referir, era absolutamente imposible que se redactaran durante las pocas sesiones de Cortes celebradas, dadas las dificultades puramente materiales existentes, siquiera fuese para seleccionar los textos procedentes de las diferentes fuentes documentales utilizadas, reagruparlos siguiendo el orden que conocemos actualmente, negociar y debatir antes de la redacción definitiva y, finalmente, promulgarlos.

La documentación conocida actualmente no contiene información alguna de cuándo se llevó a cabo la convocatoria de Cortes en Huesca, pero sí nos dice que el rey Jaime I, que era quien tenía que presidirlas, todavía se encontraba en Zaragoza el día 17 de diciembre de $1246,{ }^{19}$ lo que significa que a poco que tardara en desplazarse a Huesca con su cortejo, caso que lo hiciera en esa fecha, su viaje duraría al menos un par de jornadas y aún pasaría algun día más antes del comienzo de las sesiones. En cuanto a su clausura se refiere, no sabemos la fecha exacta pero sí muy aproximada, pues el día 6 de enero de $1247,,^{20}$ con los Fueros aprobados y promulgados por el rey, éste ordenó al

19 La estancia de Jaime I en Zaragoza está documentada desde el 22 de noviembre y el 17 de diciembre de 1246, fecha esta última en la que promulgó un documento en el que limitaba las competencias de sus oficiales por tierras del vizcondado de Bearne, un texto muy poco conocido, que no ha sido publicado, que sepamos, en ninguno de los repertorios documentales de este monarca. El manuscrito se conserva en el Archivo de la Corona de Aragón, Cancillería, Cartas reales de Jaime I, extra series n ${ }^{\circ} 82$.

20 La indicación de que los Fueros de Huesca ya se habían aprobado el 6 de enero de 1247 procede de una cita contenida en el prólogo segundo del Vidal Mayor, que dice así: En el aynno de la Incarnatión del Nuestro Seynnor Ihesu Christo de mil e CC e XL et seis, en la era de mil et CC et LXXX ${ }^{a}$ et V, VIII ${ }^{o}$ idus del mes de genero, [el rey] con conseillo et con voluntad de todos, manda et priega al seynnor obispo de Huesqua, que fiziesse dreiturera compilatión de los Fueros así como a savio omne. Ont nós, don 
jurista y obispo de Huesca, Vidal de Canellas, que fiziesse dreiturera compilación de los Fueros, assí como savio omne, lo cual significaba, por un lado, que el texto de los Fueros estaba aprobado, y además que Vidal de Canellas no había sido el autor material de los mismos, aunque es evidente que estuvo presente en las sesiones, pues su nombre aparece entre los asistentes y, por tanto, pudo haber participado también activamente en los debates previos a la obtención del consenso de los estamentos reunidos, caso de haber sido necesario hacerlo.

\subsection{Preparación del borrador de los Fueros de 1247}

Desechando la idea de que pudieran haberse confeccionado en las dos semanas que duraron las Cortes de Huesca, para tener una idea aproximada del tiempo necesario para llevar a cabo la preparación y redacción de los Fueros de 1247, hemos de tratar de averiguarlo a través de la comparación con alguno de los ejemplos parecidos de su época, de los que tenemos algún tipo de información al respecto. Así pues, si para redactar la Costum de la ciutat e regne de València de 1238, que consta de un total aproximado de 1475 artículos o fueros, se tardaron nueve meses en completarlos; y si casi otro tanto podemos afirmar de las Costumes de Tortosa redactadas entre 1272 y 1273, que tienen una extensión similar a las leyes valencianas; para una obra de 336 artículos que, como en Valencia, redactaron los juristas de la Cancillería Real, habríamos de suponer para los nuevos Fueros de Aragón un tiempo de redacción proporcional, y por tanto no debería ser inferior a dos o tres meses.

Vidal de Canelas, por la gracia de Diús obispo de Huesqua, por mandamiento del glorioso seynor rey devantdito, ordenamos los Fueros según diús, con bona et dreiturera e sana conscientia... Al haber detectado errores de transcripción en la edición que habitualmente usan todos los historiadores (Tilander, 1956: 9), hemos realizado una nueva lectura de este fragmento de texto a partir de una reproducción del manuscrito original (f. 2r), conservado en la Fundación Getty, en Malibú (California), ms. Ludwig XIV 6, datado hacia 1290-1310. Los errores son sólo dos en este caso, aunque significativos: en el manuscrito, el año de la Encarnación es 1246, y por ese motivo el escribano puso mil e CC e XL et seis, sin embargo Tilander transcribió et siete y lo reconoce en nota 5 al pie, no reparando, seguramente, en que los sistemas de datación de la Encarnación y de la Era Hispánica son distintos, y así lo dejó en evidencia el autor de la obra, de manera que nosotros ahora, cuando encontramos algún documento fechado entre el 1 de enero y el 25 de marzo, sabemos que hemos de añadir un año más para convertirlos al cómputo actual de los años, pero no podemos cambiar unilateralmente lo que escribió el notario que lo hizo. Por otro lado, respecto de la palabra dius que figura dos veces en dicho fragmento, tiene distintos significados y por tanto distinta transcripción: la primera ha de ser Diús (Dios) y la segunda diús (un poco más adelante en el mismo prólogo escrita con la forma de iuso, y significa «después»o «más abajo». 
Lo que no sabemos es cuándo comenzaron los juristas de la Cancillería Real a trabajar en el borrador del texto. Y además, hay que tener en cuenta que para poder iniciarlo no solo era necesario tener una idea muy clara de lo que se pretendía, sino poder disponer de las fuentes documentales necesarias que, a posteriori, sabemos que casi todas ellas eran de procedencia aragonesa, pero en origen no sabemos si los juristas del rey tenían otras pretensiones y más adelante tuvieron que mudar de criterio. En ese supuesto, tampoco sabemos si en los archivos de la Cancillería Real existía copia de todos los ordenamientos jurídicos necesarios para comenzar las tareas de redacción de dicho borrador de los nuevos Fueros, o si tuvieron que solicitar a los representantes de las brazos de las Cortes copias de los textos precisos, lo cual, en cualquiera de las variables, supone un tiempo muy superior al que la brevedad de la asamblea deja entrever.

Como en el prólogo de los Fueros se dice que el rey quiso aprovechar el tiempo de paz que se abrió tras la finalización de la campaña militar de conquista del reino de Valencia, nos hemos de ceñir a un periodo de tiempo que va desde mediados de 1245 hasta finales de 1246, es decir, aproximadamente año y medio, tiempo suficiente para establecer contactos, reunir documentos y redactar un buen borrador del texto que, finalmente, pudo ser sometido a juicio de las Cortes $^{21}$ aragonesas a finales de 1246, y aprobado en la primera semana de 1247 en un solemne acto con el que se iniciaba una era nueva en la historia del derecho aragonés.

\subsection{Fuentes documentales de los Fueros de 1247}

La voluntad del rey estaba clara: el reino de Aragón era el más antiguo de los estados de la corona aragonesa y necesitaba un derecho territorial. El problema, sin embargo, consistía en definir el tipo de obra que se quería o se podía realizar, tarea que estaba encomendada a los juristas de la Cancillería Real. Estos, sin embargo, no podían actuar con plena libertad, como hicieron en Valencia en 1238, pues si en aquella ocasión actuaron a su gusto y redactaron un texto extenso basado en la antigua legislación romano-justinianea, sabían que en Aragón las circunstancias eran otras y tratar de introducir el ius com-

21 Es muy probable que todo hubiese quedado ya negociado y resuelto entre las partes en el momento de dar comienzo a las sesiones de las Cortes, porque es muy difícil poder aceptar literalmente la frase del prólogo, en la que se dice que el texto fue leído y después aprobado por todos los asistentes, circunstancia un tanto sorprendente pues, no hay que olvidarlo, es muy improbable que los nobles y los representantes de las ciudades supieran latín y derecho suficiente, para poder seguir la lectura del nuevo articulado foral y además entenderlo. 
mune una utopía; por tanto tuvieron que adaptarse a la realidad de la situación y volver a edificar con los materiales ya existentes.

Es probable que hubiera dudas a la hora de seleccionar los textos, puesto que en Aragón había varias tradiciones jurídicas, algunas de ellas muy potentes, aunque muy pronto debió primar la opción del derecho que más se utilizaba en el centro y norte del reino, porque no solo la capital sino también varias de las poblaciones más importantes de dicho territorio empleaban, aunque con ciertas diferencias, el modelo común del Fuero latino extenso de Jaca. Es conveniente precisar, sin embargo, que el cuerpo legal jacetano empleado en la redacción de los Fueros de 1247, no es exactamente el mismo que se utilizó en Zaragoza a partir de 1119, sino una forma un poco más desarrollada del mismo, que se corresponde con las versiones en romance conocidas actualmente; lo que significa que, gracias a esta circunstancia y al hecho de que los Fueros de 1247 se redactaron originalmente en latín, podemos conocer de manera muy aproximada el aspecto que tenía la versión latina desarrollada del Fuero extenso de Jaca, en los casi dos centenares de artículos que se utilizaron en el ordenamiento de 1247.

Además del Fuero latino extenso de Jaca, a fecha de hoy hemos podido identificar otras fuentes documentales utilizadas en la redacción de estos fueros aragoneses. Se trata del Fuero de Estella de 1164 (Lacarra/Martín, 1969), del que proceden algo más de una veintena de artículos (García Edo, 2015: 360-380), el privilegio o carta de fueros de las Cortes convocadas en 1208 por Pedro II, así como un conjunto significativo de privilegios reales otorgados por el rey Jaime I a los aragoneses, con anterioridad a los Fueros. Faltan todavía por identificar unos 30-35 artículos.

Todas estas otras fuentes documentales también se redactaron originalmente en latín, por lo que es un tanto absurdo afirmar, como hacen algunos historiadores, que los juristas, tanto los que estaban al servicio de la Cancillería Real como cualesquiera otros que trabajasen a sueldo de nobles y caballeros, o para las ciudades y villas aragonesas, todos perfectos conocedores del derecho aragonés y del latín, escribieran en romance aragonés los Fueros de 1247 y, una vez aprobados por las Cortes, los tradujeran de nuevo al latín, que es la versión oficial de los mismos, sin salirse ni un ápice del texto de las distintas fuentes documentales originales, cosa materialmente imposible.

La suma de los artículos de todas las fuentes conocidas de los Fueros de Aragón supone el $89 \%$ de los 336 artículos de que estos constaban según el 
manuscrito de la Catedral de Tortosa citado anteriormente, lo cual nos permite afirmar que los legisladores no hicieron otra cosa sino componer un texto basado en su práctica totalidad en fuentes de derecho aragonés de carácter local vigente en esos momentos, aunque común a bastantes poblaciones del reino, así como otros textos otorgados por la institución monárquica desde comienzos del siglo XIII e igualmente vigentes. Por lo que Aragón adquirió como carta de identidad de todo el reino una repetición de cuanto ya conocía y le era propio, y se negó o, simplemente no se planteó, abrirse a nuevos campos, con mano de las propuestas que de haberse aprobado hubieran efectuado, sin duda alguna, los asesores legales y los notarios de la Cancillería Real - que ya habían hecho del ius commune de tradición romano-justinianea un extraordinario banco de pruebas en un texto legislativo extenso, cuando redactaron en 1238 la Costum de la ciutat e regne de València. Aragón decidió seguir su propio camino, y al rey Jaime I no debió quedarle otra opción sino la de buscar una solución práctica, a través del encargo a Vidal de Canellas del libro que conocemos como Vidal Mayor, del que más adelante nos ocuparemos.

Veamos ahora algunas de las características de todos estos textos legales, pues poca atención se les ha prestado hasta el momento, a pesar de que sin ellos no hay manera de entender de manera global el proceso de redacción de los Fueros de Aragón de 1247.

1.- Fuero latino extenso de Jaca ${ }^{22}$

2.- La versión C del Fuero extenso de Jaca ${ }^{23}$

3.- Fuero de Estella de 1164

4.- Fueros de Aragón de las Cortes de 1208

5.- Documentos de la Cancillería de Jaime I

6.- Fueros no identificados

\subsubsection{El Fuero latino extenso de Jaca}

La fuente principal de la redacción de los aproximadamente 336 artículos de los Fueros de Aragón de 1247 la constituye la versión última del Fuero latino extenso de Jaca, surgida en el paso del siglo XI al XII y ampliada a lo largo de esta última centuria, dando lugar a una nueva versión de la 
cual actualmente no conocemos la existencia de manuscrito alguno, aunque sí una traducción romance del mismo, efectuada a finales del siglo XIII o comienzos del XIV y que recibe el nombre de Versión A de dicho fuero desde su publicación (Molho, 1964: 15-162). Aproximadamente 168 de los 313 artículos de este fuero extenso de Jaca se incorporaron al nuevo articulado de los Fueros de Aragón de 1247, lo que viene a representar un 50\% del total. $^{24}$

\subsubsection{La llamada versión C del Fuero latino extenso de Jaca}

La segunda fuente documental en importancia es un texto derivado del Fuero extenso de Jaca, solo conocido en versión romance y señalado con la letra C desde que se publicó (Molho, 1964: 300-502). Consta de 325 artículos y, al compararla con la versión $\mathrm{A}$, comprobamos que coinciden únicamente en unos 140 artículos, lo que significa que alrededor de 185 artículos de esta versión $\mathrm{C}$ se redactaron en otro momento, seguramente posterior a la redacción A, que se considera la más antigua. En 1247 un manuscrito de esa versión C estaba en manos de los juristas de la Cancillería, quienes incorporaron 84 de sus artículos al texto de los nuevos Fueros de Aragón. ${ }^{25}$

\subsubsection{Fuero de Estella de 1164}

Aunque es muy conocida la influencia que ejerció el Fuero latino extenso de Jaca en el derecho navarro, en cambio no lo es el hecho de que en 1247 la Cancillería Real de Jaime I utilizó como fuente documental de los Fueros de Aragón, el Fuero de 1164 de la población navarra de Estella (García Edo, 2015: 360-380), a partir del cual se redactaron un total de 26 fueros nuevos, en bastantes casos transcritos literalmente, de los cuales destacamos, por su posición, los artículos 1 y 2 de los fueros aragoneses, que se refieren a las penas en que incurrirían quienes asaltasen las iglesias o agrediesen a eclesiásticos, una singularidad aunque solo hasta cierto punto, pues era frecuente que en los textos legislativos se hablase en primer lugar del derecho de Dios, como es el caso, y después del de los hombres, lo cual sucede a partir del tercer fuero.

24 Por razones de espacio no podemos detallarlos en este artículo. Pueden identificarse a partir de las tablas confeccionadas por Delgado Echeverría, 2004: 161-194.

25 Delgado Echeverría, 2004: 161-194. 


\subsubsection{Fueros de Aragón de las Cortes de 1208}

En enero de 1188 el rey Alfonso II de Aragón celebró Cortes en Huesca; en ellas se promulgaron un total de 12 disposiciones o fueros, con carácter territorial, tal como se desprende de la copia llegada a nuestros días. Sin embargo y por lo que sabemos en estos momentos, no parece que se utilizaran en la redacción de los Fueros de 1247. A diferencia, sí se utilizaron los acuerdos de la segunda asamblea de Cortes aragonesas, celebrada en mayo de 1208 por el rey Pedro II de Aragón ${ }^{26}$ también en la ciudad de Huesca; en ella se dictaron 21 artículos o fueros, de los cuales 17 se trasladaron a los nuevos Fueros de Aragón, catorce directamente y tres por vía indirecta, pues previamente habían sido aprovechados por los juristas de la Cancillería para componer otros tantos párrafos del texto de las Constituciones de Paz y Tregua concedidas por Jaime I a los aragoneses en el año 1235; el texto completo de estos tres párrafos de las constituciones se incorporó a los Fueros de Aragón.

\subsubsection{Documentos de la Cancillería de Jaime I}

En los Fueros de 1247 y, a pesar de su notable extensión, suelen pasar bastante desapercibidos los privilegios reales aragoneses, copiados a veces completos e integrados en el cuerpo general de su articulado. Son una rareza, incluso una extravagancia, porque los términos fuero y privilegio tienen un origen y un significado distintos, pero a veces los segundos se integran artificialmente en la posición que por temática les corresponde dentro de los primeros, bien sea por voluntad del rey, de los legisladores, o de los copistas de los manuscritos, que llevan a cabo una acción de esa naturaleza por razones de comodidad o de operatividad. No se trata, a veces, de documentos completos sino de artículos sueltos o fragmentos de la parte dispositiva de los mismos y, al cabo del tiempo, de muchos años incluso, al pasarlos a otro soporte, esas adiciones se regularizan e incorporan al cuerpo legislativo general como si se tratase de verdaderos fueros.$^{27} \mathrm{~A}$ fecha de hoy pueden identificarse en los Fueros de Aragón de

26 El documento fue publicado por Molho (1964: 165-177), pero no nos consta que se hayan estudiado hasta el momento sus vínculos con el texto, algo que realizaremos en breve, pues en el momento de redactar estas líneas, también se encuentra en proceso de realización el oportuno estudio en el que se analizará con detalle la plasmación casi completa de este privilegio de 1208 en el articulado de los Fueros de Aragón de 1247.

27 Ese mismo criterio se aplicó a la Costum o Fueros de Valencia de 1238, a los que se añadieron numerosos fragmentos de privilegios reales fechados entre 1239 y 1253 y, cuando se actualizaron los Fueros en 1261, esos fragmentos (alrededor de 25) se incorporaron al cuerpo legislativo como si hubieran formado parte del mismo desde un principio. 
1247, un total de 19 disposiciones procedentes de distintos privilegios completos u otro tipo de concesiones reales. La mayoría son textos preexistentes promulgados durante los reinados de Pedro II y su hijo Jaime I de Aragón, pero hay un par de ellos que aparentan haber sido redactados expresamente por los juristas de la Cancillería Real, con motivo de la redacción del Código de 1247.

De esos 19 documentos, y de acuerdo con el manuscrito de la catedral de Tortosa que nos sirve de referente, 9 se encuentran copiados entre los 336 fueros de que consta el cuerpo legal de esta versión, y los 10 restantes se encuentran copiados a continuación, formando parte de las adiciones realizadas a lo largo del reinado de Jaime I. Esta posición no es la misma en todos los manuscritos latinos conocidos actualmente de los Fueros de Aragón. También hay en algunos manuscritos copias de tres privilegios reales que no figuran en el de Tortosa, y es probable que se incorporaran a los Fueros de 1247 bastantes años después, tal vez incluso después de la muerte de Jaime I, de los cuales también dejamos constancia por considerarlo de interés.

Los 9 fueros del códice de Tortosa que proceden de la Cancillería Real y se incorporaron al cuerpo de los Fueros de 1247 son los que figuran a continuación, citados a partir de las primeras palabras con las que dan comienzo, después de la intitulación real, en su caso:

1. Universis terrarum atque regnorum... ${ }^{28}$

2. Statuimus firmiter precipiendo... ${ }^{29}$

3. Constituit rex Iacobus quod pater.... ${ }^{30}$

4. Statuit rex Petrus quod magnates... ${ }^{31}$

5. Statutum est quod homines... ${ }^{32}$

6. Intendentes paci et tregue tocius... ${ }^{33}$

7. Constituit rex Iacobus quod si animal... ${ }^{34}$

8. Item, constituit quod si homo occiderit... ${ }^{35}$

9. Ad honorem eius qui dixit: Non... ${ }^{36}$

30 Edición incunable de 1476-77, f. 31r. Sin fecha.

31 Edición incunable de 1476-77, f. 34r. Sin fecha. Es del reinado de Pedro II.

32 Edición incunable de 1476-77, f. 34r. Sin fecha. Es del reinado de Pedro II.

33 Edición incunable de 1476-77, f. 34v. Fechado en 1227.

34 Edición incunable de 1476-77, f. 42r. Sin fecha.

35 Edición incunable de 1476-77, f. 42r. Sin fecha.

36 Edición incunable de 1476-77, f. 45v. Sin fecha. 
Los 10 fueros del códice de Tortosa que proceden de la Cancillería Real, pero figuran como adiciones a los Fueros de 1247, son los siguientes:

1. Nullus in sacris ordinibus... ${ }^{37}$

2. Actor ponatur in possessione... ${ }^{38}$

3. Appellare constituit rex Iacobus... ${ }^{39}$

4. Iuras tu iudeus, per illum...40

5. Item, si infançon a rege... ${ }^{41}$

6. Dixit dominus rex apud Turolium... ${ }^{42}$

7. Sacramentum sarracenorum... ${ }^{43}$

8. Establimos e femos fueros nuevos... ${ }^{44}$

9. In Dei nomine. Cum status... ${ }^{5}$

10. Per nos et omnes successores... ${ }^{46}$

Los 3 fueros que no figuran en el códice de Tortosa y que, procedentes de la Cancillería Real, se encuentran en otros manuscritos de los Fueros de Aragón de 1247 son los siguientes:

1. Paci et treuge totius regni Aragonum... ${ }^{47}$

2. Rex potest monetam quantamcumque... ${ }^{48}$

3. Quando super confirmatione... ${ }^{49}$

\subsubsection{Fueros por identificar}

A fecha de hoy queda por identificar la fuente documental de unos 3035 artículos del cuerpo legal de 1247, según la versión del manuscrito de Tortosa.

37 Edición incunable de 1476-77, f. 45v. Sin fecha.

38 Edición incunable de 1476-77, f. 46r. Sin fecha.

39 Edición incunable de 1476-77, f. 45v. Sin fecha.

40 Edición incunable de 1476-77, f. 47v. Fechado en 1241.

41 Edición incunable de 1476-77, f. 46v. Sin fecha.

42 Edición incunable de 1476-77, f. 46r. Fechado en 1259.

43 Edición incunable de 1476-77, f. 49v. Fechado en 1241.

44 Edición incunable de 1476-77, f. 47r. Fechado en 1265.

45 Edición incunable de 1476-77, f. 37r. Fechado en 1236.

46 Edición incunable de 1476-77, f. 39r. Fechado en 1243.

47 Edición incunable de 1476-77, f. 36r. Fechado en 1235.

48 Edición incunable de 1476-77, f. 37r. Sin fecha.

49 Edición incunable de 1476-77, f. 38v. Sin fecha. 


\section{Derecho canónico en los Fueros de Aragón de 1247}

Existe un buen estudio que hace un interesante análisis de la importancia de la canonística en el articulado de los Fueros de 1247 (García García, 1996: 27-41), aunque en nuestra opinión parte de un juicio erróneo, al apoyarse en el hecho de que «entre los confirmantes de sus normas se contaban muchos obispos y otros prelados», lo cual contrasta con la breve relación de los mismos que, según el prólogo de los Fueros son únicamente dos, los obispos de Zaragoza y Huesca, quienes asistieron a la asamblea de Cortes aragonesas como era su obligación y su derecho, al formar parte del estamento eclesiástico de las mismas. Sin embargo, no es este el argumento principal de nuestro desacuerdo, sino el hecho de que cuando analizamos todos los fueros vinculados al derecho canónico que cita dicho autor, casi en ningún caso se trata de textos nuevos sino redacciones preexistentes.

Salvo error, únicamente son dos los artículos que parecen haberse redactado adrede para los Fueros de 1247. El primero ${ }^{50}$ se refiere a la regulación de los días festivos en el calendario judicial, que seguía los preceptos que marcaba la Iglesia, razón por la cual se prohibía cualquier actividad en los tribunales de justicia los domingos y demás fiestas de guardar. Sin embargo, y dada la permanente itinerancia del rey a lo largo y ancho de la geografía de los reinos de la corona aragonesa, la curia regia podría despachar cualquiera de esos días, si encontrándose de paso en algún lugar del reino de Aragón se viera en la necesidad de hacerlo.

Más importante parece la prohibición de la práctica de lo que se venía llamando el juicio de Dios, interpretado a partir de la prueba del hierro candente, la del agua hirviendo o cualquier otra similar, a la que eran sometidos los acusados de determinados delitos. Este fuero sigue la doctrina del derecho canónico al respecto, aunque llama la atención el hecho de que tratándose de una disposición que afectaba únicamente al reino de Aragón, el monarca la hizo extensiva a todos los reinos y señoríos de su corona y, por esta declaración, se evidencia con claridad que la redacción fue obra de los juristas de la Cancillería Real..$^{51}$

50 Da comienzo con las palabras Omni tempore fiat y se localiza al folio 18r de la edición incunable de 1476-77.

51 Da comienzo con las palabras: Ad honorem eius y es el último fuero de la compilación de 1247. Se corresponde con el fuero 336 del manuscrito de Tortosa, y se localiza en el folio 45v de la edición incunable de 1476-77. 


\section{7. ¿Qué aprobaron las Cortes aragonesas en 1247 ?}

Todo el trabajo llevado a cabo por los juristas de la Cancillería Real dio como resultado una obra distribuida en ocho libros o partes, dispuesta con un cierto orden y coherencia y constituyendo un texto que en su conjunto constaba de alrededor de 336 artículos o fueros, según la versión del manuscrito de Tortosa, si bien hay pequeñas diferencias, en cuanto al número y ubicación de algunos artículos cuando lo comparamos con los restantes manuscritos conocidos, ninguno de los cuales puede considerarse prototipo de los demás, según se desprende de la tabla realizada al efecto.

Así pues, de acuerdo con el contenido del manuscrito de Tortosa, la distribución de los Fueros de Jaime I por libros y rúbricas es la siguiente:

\begin{tabular}{|l|l|l|}
\hline$N^{o}$ orden & Fueros & Título de su primera rúbrica \\
\hline Libro 1 & $1-75$ & De sacro sanctis ecclesiis \\
\hline Libro 2 & $76-140$ & De privilegio absentium causa rei publice \\
\hline Libro 3 & $141-180$ & De pena temere litigantium \\
\hline Libro 4 & $181-218$ & De mandati \\
\hline Libro 5 & $219-239$ & De prohibitis donationibus \\
\hline Libro 6 & $240-259$ & De conditione infançonatus \\
\hline Libro 7 & $260-285$ & De pace \\
\hline Libro 8 & $286-336$ & De custodibus carcerum \\
\hline
\end{tabular}

Los manuscritos latinos de los Fueros de 1247 no señalan el lugar en donde finaliza la obra y comienzan las adiciones efectuadas durante el resto del reinado de Jaime I. Pero, en cambio, sí aparece una clara indicación de final en dos de los manuscritos que transmiten versiones, y en ambas lo hacen tras el fuero en romance del texto..$^{52}$ Eso se corrresponde con el fuero Ad honorem eius qui dixit "non temptabis dominum Deum tuum", canden-

52 En el manuscrito 458 de la Biblioteca Nacional de España, que está datado en la primera mitad del siglo XIV, figura la siguiente inscripción en latín: Explicit liber fororum Aragonie (Tilander, 1937) y en el manuscrito del Ayuntamiento de Miravete de la Sierra (Gargallo Moya, 1992) que algunos datan a finales del siglo XIII, aunque más bien aparenta ser de bien avanzado el XIV, leemos en romance: Aquí es acabado el libro de los fueros d'Aragón. Por su notable antigüedad y por no derivarse interés o beneficio alguno al hacer tal afirmación, no hay razones para dudar de tan interesante indicación hecha en dos momentos y circunstancias distintas. 
tis ferri..., relativo a la prohibición del juicio de Dios, al que nos acabamos de referir.

\section{Adiciones efectuadas durante el resto del reinado de Jaime I}

El manuscrito de Tortosa contiene todavía 30 fueros más, hasta un total de 366, que suponemos añadidos por orden cronológico, lo cual parece lógico, si bien solo uno de ellos - inserto en la rúbrica De elongatione debitorum y que da comienzo con las palabras Dixit dominus rex apud Turolium-, está fechado (octubre de 1259). Algunos fueros posteriores a éste son, en realidad, transcripciones de privilegios reales anteriores a 1247, que pudieron haberse incorporado en cualquier momento en atención a su interés. La relación finaliza con un fuero relativo a los daños causados por perros de caza, único de la rúbrica De canibus de caça.

Queremos hacer mención ahora al hecho de que el anónimo escribano del manuscrito dejó en ese punto concreto del manuscrito un claro espacio en blanco, para transcribir a continuación el texto de los mal llamados Fueros de Ejea de 1265. Aunque habitualmente se les califique como fueros nuevos, en realidad no son producto de una asamblea de Cortes, sino de un pacto a distancia entre el rey Jaime I y la alta nobleza aragonesa de la época, en un momento de duro enfrentamiento entre ambas partes por razones políticas que no interesan en esta ocasión. Durante las negociaciones, las comunicaciones entre bandos se realizaron a través de mensajeros desde lugares distintos del entorno de Ejea, y todos con las armas listas por si fuera necesario utilizarlas. Las disputas finalizaron con la aceptación por parte del rey de las diez peticiones que fueron solicitadas por la nobleza. De este documento, tal como figura incluido en la versión del manuscrito de Tortosa, nos interesa destacar dos características particulares: la primera es que nos facilita la versión latina del texto del acuerdo, cuando todas las demás copias conocidas hasta el momento están escritas en aragonés y, la segunda, que omite una cláusula que sí figura en el resto de manuscritos, mediante la cual el rey disponía que en adelante el Justicia de Aragón fuera siempre un caballero. ${ }^{53}$

53 En un cuaderno aparte de este mismo manuscrito hay una versión romance de estos Fueros de Ejea, en la que también se omite la cláusula relativa a la figura del Justicia de Aragón que acabamos de citar, lo que nos hace dudar de si ya figuraría en origen o, por el contrario, pudo tratarse de una adición efectuada con posterioridad en circunstancias que desconocemos. 


\section{Los fueros dudosos de Jaime I de 1247}

Hace casi una década se publicó la edición crítica de la versión original latina de los Fueros de Aragón de 1247 (Pérez Martín, 2010), en cuyo estudio preliminar se dieron a conocer las características de los once manuscritos medievales de los mismos llegados a nuestros días, así como las similitudes y diferencias que presenta cada uno de los diez primeros al ponerlos en comparación con el que le sirvió de referencia para llevar a cabo su trabajo. Este no es otro sino el del manuscrito más reciente de dichos fueros aragoneses, conservado en la biblioteca del castillo de Perelada. Es de finales del siglo XV según este autor y sirvió de base para la realización de la primera edición incunable de los Fueros de 1476-77, hasta el punto que el manuscrito, dice, «coincide plenamente con el texto impreso [...] incluso en los errores». ${ }^{54}$

Pues bien, dichos diez manuscritos, todos del siglo XIV y primera mitad del siglo XV, omiten un número variable de fueros que, sin embargo sí están en el manuscrito de Perelada. Es difícil evaluar dichas omisiones, si no se hace a través de una tabla informatizada que permita hacer una comparación de todos ellos, realizada la cual y, salvo error, hemos podido constatar que el número de fueros que únicamente figuran en el manuscrito de Perelada es de 17, a saber:

\begin{tabular}{|l|l|l|}
\hline 1 & Si equus, equa, mulus... & $1.3 .36^{55}$ \\
\hline 2 & Statuimus ut vir sine... & 2.5 .2 \\
\hline 3 & Item, . ullum debitum... & 2.13 .6 \\
\hline 4 & Si lis vertitur inter... & 3.7 .5 \\
\hline 5 & Si unus frater... & 3.9 .5 \\
\hline 6 & Si filius remanserit... & 3.9 .8 \\
\hline 7 & Item, si aliquis habuerit... & 3.10 .4 \\
\hline 8 & Nullus homo cuius... & 4.3 .4 \\
\hline 9 & Cuiuscumque conditionis... & 4.3 .5 \\
\hline 10 & Si conductum animal... & 4.4 .2 \\
\hline 11 & Qualiscumque homo... & 4.13 .3 \\
\hline
\end{tabular}

54 Pérez Martín, 2010: 44-48

55 Esta triple numeración por libro/título/fuero de los Fueros de Aragón, es la manera de citarlos que figura en la edición de Pérez Martín, 2010: 31, y así lo trasladamos a estas páginas. 


\begin{tabular}{|l|l|l|}
\hline 12 & Ad refrenandam... & 4.13 .4 \\
\hline 13 & Forus est quod si... & 5.2 .2 \\
\hline 14 & Quando super... & 7.7 .3 \\
\hline 15 & Forus antiquus est... & 7.17 .2 \\
\hline 16 & Quicumque fuerit consultor... & 7.20 .1 \\
\hline 17 & Si autem pro debitis... & 8.7 .7 \\
\hline
\end{tabular}

Este número ${ }^{56}$ es muy inferior al que figura en la edición crítica, que asciende a 27 fueros, aunque esa circunstancia tiene una explicación bastante clara, a partir de una nota que figura en el manuscrito de Perelada, al comienzo del libro, justo al final de la tabla alfabética del contenido de los fueros, y que se refiere precisamente a estos fueros extravagantes, que en dicho volumen se señalan con dos puntos negros puestos dentro de la letra capital de cada uno de ellos, o al lado:

Fori habentes duos punctos nigros intus caputliteram, vel ad latera, fuerunt adinventi in aliquibus voluminibus fororum antiquorum; sunt signati, ut cognoscantur; et sunt inserti, ne aliunde perquirantur: vel margines deturpent..$^{57}$

Entendemos que el anónimo copista de la segunda mitad del siglo XV quiso hacer una compilación lo más completa y perfecta posible y, sin dudar de su buena voluntad, bien a partir de un ejemplar manuscrito que obrase en su poder, o que se molestó en encargar o realizar por sí mismo, posteriormente y por iniciativa propia se preocupó de cotejar su contenido con el de otros manuscritos de los Fueros que pudieran estar en manos de diferentes instituciones o particulares, y añadió todos aquellos textos que consideraba que figuraban como fueros en dichos manuscritos, pero no en el suyo. Una vez satisfecho con el resultado, realizó o encargó la confección de una copia de cierta solemnidad, con el texto todo seguido, limpio y cuidado, en donde hizo la advertencia de la procedencia de los textos señalados con puntos, como acabamos de mencionar. Del total de tales 27 fueros, según cómputo en la edición crítica,

56 Los resultados de la edición citada en la nota anterior no coinciden con los nuestros, aunque en estos momentos no son necesarias mayores explicaciones pues, en realidad, lo único que interesa destacar es el hecho de que no todos los Fueros de 1247 atribuidos a Jaime I lo son en realidad.

57 Pérez Martín, 2010: 47-48. 
hemos podido comprobar que 10 sí que figuran en alguno de los otros manuscritos llegados a nuestros días pero no en la mayoría ni tampoco en los más antiguos. Y, respecto de los 17 restantes, efectivamente, no tenemos noticia alguna hasta su inclusión en el manuscrito de Perelada; lo cual nos hace dudar de si realmente unos y otros procedían de la redacción primitiva, o se trataba de añadidos realizados en diferentes momentos a lo largo del siglo XV, por conductos y por razones que en este momento no son conocidas. Sea como sea, estos añadidos pasaron a ser considerados como auténticos fueros de Jaime I a partir de la edición incunable de 1476-77, algo que está muy lejos de corresponderse con la realidad.

No es momento ahora para dedicar más tiempo al asunto, aunque sí para advertir del hecho, ya que eso significaría que alrededor de un $8 \%$ de los Fueros de 1247 - un porcentaje nada despreciable - , en realidad tienen un origen bastante dudoso.

\section{El Vidal Mayor, un encargo un tanto singular}

El encargo del rey Jaime I, antes referido, fue muy concreto y la persona de Vidal de Canellas, obispo de Huesca, la idónea para materializarlo, pues no solo era un destacable miembro de la Iglesia y, por tanto, persona nada sospechosa para los aragoneses, sino además reputado jurista formado en la universidad de Bolonia, razones más que suficientes para considerarle capaz de escribir un libro que sirviera para interpretar mejor los Fueros recién aprobados ya que, al estar basados casi exclusivamente en fuentes de derecho aragonés vigente, era necesario disponer de una obra complementaria que pusiera en relación ese viejo derecho nuevo con las corrientes de pensamiento jurídico de procedencia italiana que estaban expandiéndose de forma imparable por gran parte de Europa Occidental y a las que ni el rey Jaime I ni los juristas de la Cancillería Real podían darles la espalda, por ser un fenómeno de tanta envergadura y trascendencia que, a finales del siglo XIII, se apoderaría de las mentes y los modos de practicar el derecho de todos los juristas en ejercicio en esos momentos en los reinos de la Corona de Aragón. ${ }^{58}$

58 Se trata del Vidal Mayor, considerado por muchos historiadores como una segunda versión oficial y más extensa de los Fueros de Aragón, lo cual no es en modo alguno cierto, puesto que una vez que don Vidal de Canellas lo redactara nunca fue impuesto por el rey ni presentado ante una nueva asamblea de Cortes de Aragón, por lo que quedó para siempre como una espléndida obra de derecho, para con- 
Conviene destacar que cuando el rey pidió al obispo que hiciese una dreiturera compilation, la primera palabra no significaba únicamente que había de ser recta, justa, o correcta, - puesto que así entendida en la petición del rey, sería como descalificar el trabajo recién aprobado por las Cortes y promulgado por la Corona-, sino que ofrecía la posibilidad de llevar a cabo una obra mucho más amplia y abierta a la introducción de adiciones de naturaleza muy diversa, entre las cuales cabían a la perfección las procedentes de los textos de ius commune, que no era otra cosa sino la forma con que se denominaba al derecho que desde hacía más de un siglo se venía estudiando y enseñando en la Universidad de Bolonia, basado en el análisis y adecuación del antiguo derecho romano-justinianeo a las necesidades que en materia jurídica pudiera tener la sociedad europea de la época, plasmándolo tanto en las prácticas diarias de los tribunales de justicia como en la redacción de sus respectivos ordenamientos jurídicos de carácter territorial. ${ }^{59}$

No era tarea fácil, sin embargo, la de hacer concordar los textos romanos con los forales, como pone de manifiesto el propio Vidal de Canellas al final del prólogo de su obra, pero para salvar su responsabilidad lo explica, advirtiendo cuál había sido su solución al respecto:

E otrosí, maguer que avemos feito mentión a cada començamientos de los libros, de sendos títulos, empero cada un libro d'estos IX libros ha sus títulos, seguiendo ordenadament de cada materia, segúnt que está escripto de iuso más complido et más ordenament. Et otrosí de los quoales libros ordenamos algunos títulos seguientes, e por el desacordamiento del dreito

sulta de juristas, sin valor legal alguno. A pesar de ello son bastantes los historiadores que piensan que los Fueros de Aragón y el Vidal Mayor son, respectivamente, una compilación Minor y otra Maior, respectivamente, de los fueros aragoneses, lo que equivaldría a decir que en el reino de Aragón hubo a partir de 1247 dos textos constitucionales simultáneos, lo cual ni era posible ni tenía sentido. Como es natural y a la luz del conocimiento que nos proporciona toda la documentación foral aragonesa de los siglos XII y XIII llegada a nuestros días, no podemos en modo alguno compartir esta opinión y algunas otras de naturaleza menor, derivadas de la misma, a las que hemos tratado de responder en todos los casos a través de la redacción de estas páginas, aunque deberá tener un tratamiento y una extensión mucho mayor en otro momento, a través de una monografía sobre los Fueros de Aragón de 1247, según la versión del manuscrito de la catedral de Tortosa, el más antiguo conocido, que puede arrojar mayor luz a todo el proceso de gestación del primer gran texto legislativo aragonés que nos ocupa ahora.

$59 \mathrm{Y}$ en el nivel práctico que supone este encargo, significaba poder relacionar el orden seguido en la redacción de los ocho libros de los Fueros de Aragón, que en parte ya se había intentado distribuir de ese modo, con el esquema de los nueve libros del Códex de Justiniano, considerado un referente en el siglo XIII a la hora de hacer consultas puntuales y citas de textos, así como para redactar nuevas leyes de carácter singular, o incluso textos legislativos extensos, como el de la Costum de la ciutat e Regne de València de 1238, distribuida siguiente el orden del código romano, o la Costum de Tortosa de 1273 , basada en parte en la valenciana, que siguió ese mismo sistema. 
et del fuero oviémoslo a ordenar en otra manera, assí como es de fazer las peyndras et de los peynnos, e como las peyndras sean cosas avantables en iuditio segúnt costumpne d'este fuero, los títulos d'eillos entre los appareillamientos de iuditio lo poniemos $[\ldots]^{60}$

Llevado este asunto a la realidad del reino de Aragón, conviene señalar que Vidal de Canellas no tenía como misión la de escribir un libro que sustituyera a los nuevos fueros aragoneses, sino que los explicara a los juristas que lo leyesen, de modo que llevó a cabo una obra que permitía un fácil acceso al conocimiento de cualquier institución foral, pero además posibilitaba a los lectores ampliar conocimientos en muchas otras materias ya que el Vidal Mayor era muchísimo más extenso que el texto legislativo aragonés de referencia, ${ }^{61}$ así como un instrumento muy útil para agilizar acciones ante los tribunales de justicia:

Et es a ssaber que nos avemos ordenados aquestos fueros en IX libros et por sendos títulos, en tal guisa que cada I letrado más aýna trobe lo que querrá quando querrá dar iuditio, segúnt que se siegue más ordenadament por los títulos de iuso continuadament complidos et escriptos. Et otrosí, por aqueillo que muitas vezes los mezquinos omnes pierden lur dreito por alongança de iudicio, mas desd'uey más quada una iustitia, oýdo el clamo, puede entender en quoál logar del libro es el fuero que pertaynnesce ad aqueill clamo, si la iusticia es letrado, e si non fuere letrado, fága-lo guardar ad algún letrado, que aýna podrá probar aqueilla que demandará, si bien catare los títulos et bien parare mientes en el ordenamiento que se siegue. ${ }^{62}$

Por tanto, Vidal de Canellas, perfecto conocedor de ese ius commune que estudió durante sus años de estudio en Bolonia, no alteró el texto de los Fueros latinos de Aragón recién aprobados por las Cortes aragonesas y distribuidos en ocho libros o partes, ${ }^{63}$ cosa que era evidente que no podía hacer, pero tampoco nada le impedía que a la hora de realizar su trabajo, de acuerdo al dreito romano, lo hiciese dividiendo su libro en nueve partes, que son las mismas que encontramos en el Codex del emperador Justiniano, ${ }^{64}$ aunque no pudo hacer concordar de la manera que hubiera deseado los contenidos del código arago-

60 Manuscrito de la Fundación Getty: ff. 2v-3r.

61 A título meramente indicativo, diremos que el manuscrito de los Fueros de Aragón de 1247 de la catedral de Tortosa tiene 91 páginas, mientras que el Vidal Mayor tiene 553 páginas.

62 Manuscrito de la Fundación Getty: ff. 2v-3r.

63 Todos los manuscritos latinos, que son los únicos que contienen la versión oficial del texto de los Fueros, mantienen su división en ocho libros, razón por la cual no tiene sentido alguno defender una división distinta en nueve.

64 Coincide con el Códex en el número de libros, pero no en cuanto a los contenidos de los capítulos o rúbricas de cada uno de ellos. 
nés con el código romano, por las evidentes carencias del primero. Ya habrá ocasión en otro momento para analizar con mayor detalle el contenido y el significado del Vidal Mayor. Baste ahora con decir que los Fueros de Aragón promulgados a comienzos de enero de 1247 , y en lengua latina, son el único texto oficial de los mismos a partir de ese momento, y todas las adiciones que se realizaron en las tres décadas siguientes, especialmente reflejadas en el manuscrito conservado en la Catedral de Tortosa, se situaron por orden de aparición al final de ese libro octavo y último en que se dividió la obra desde el inicio; y no fue sino hasta mucho después del fallecimiento de Jaime I cuando se añadió un libro noveno, y más adelante algunos más, en los que se incluyó la nueva legislación resultante de los acuerdos tomados por las asambleas de Cortes aragonesas celebradas a lo largo del siglo XIV, cuestiones estas que no forman ahora parte de nuestro trabajo.

\section{Conclusiones}

De todo cuanto se contiene en los capítulos anteriores, que hemos tratado de explicar con la mayor claridad posible a pesar de la complejidad del análisis de las fuentes documentales utilizadas, podemos establecer las conclusiones siguientes:

Primera. El Fuero latino extenso de Jaca, redactado en gran parte a finales del siglo XI y comienzos del XII, se constituyó desde 1096 en la fuente principal del Fuero latino extenso de Huesca, y a partir de 1119 en la del Fuero latino extenso de Zaragoza. Un siglo después, también se utilizó como fuente principal para la redacción del texto original latino de los Fueros de Aragón de 1247.

Segunda. Los autores de los Fueros de 1247 fueron los juristas de la Cancillería Real, pues las huellas de su trabajo están muy presentes a lo largo de todo el articulado, tanto a través de la experta selección de los textos empleados en su redacción, a fin de darles un contenido y una estructura que anteriormente no tenían; como preocupándose por añadir de su propia mano algunos artículos necesarios, sin entrar en contradicción con el derecho aragonés preexistente, cosa que materializaron poniéndolos en boca del rey, pues solo ellos podían actuar de ese modo por razón del oficio que desempeñaban.

Tercera. De los 336 artículos de que constan los Fueros de Aragón de 1247, según la versión del códice de Tortosa, alrededor de 250 proceden de dos ma- 
nuscritos del Fuero latino extenso de Jaca, transcritos literalmente en la mayor parte de los casos.

Cuarta. Otras fuentes documentales, todas escritas en latín - Fuero de Estella, Privilegio de 1208, Documentación de la Cancillería Real-, permiten identificar unos 50 fueros más (no incluimos adiciones a los Fueros de 1247), la mayoría también copiados de forma literal a partir de dichas fuentes.

Quinta. La suma de resultados de los apartados anteriores, indica que conocemos la procedencia de alrededor del 89\% del articulado de los Fueros de 1247; lo cual nos permite afirmar que los legisladores no realizaron una obra original sino que se limitaron a adaptar textos de derecho aragonés preexistente, sin entrar a valorar otras posibilidades, lo que dio como resultado que el ius commune de tradición romano-justinianea tardase mucho en implantarse en la legislación foral aragonesa.

Sexta. Los Fueros de Aragón de 1247 se redactaron originariamente en latín, tal como lo estaban todas las fuentes documentales utilizadas; y se distribuyeron desde el primer día en ocho libros, nunca en nueve, y así se mantuvieron con carácter oficial a lo largo de toda la época foral. Desde finales del siglo XIII, comenzaron a realizarse traducciones romance de los mismos, aunque se trataba de iniciativas privadas con finalidad práctica, para acercar los Fueros a quienes desconocían la lengua latina, pero nunca sustituyeron al texto oficial latino ni adquirieron valor legal alguno.

Séptima. La comparación de todos los manuscritos latinos conocidos de los Fueros de Aragón de 1247, permite concluir que la copia del Archivo de la Catedral de Tortosa es la que transmite la versión más próxima al texto original promulgado por Jaime I, y la única que incluye a continuación lo que aparenta ser una relación completa de los otorgados desde entonces hasta la finalización de su reinado.

Octava. Esa comparación también permite comprobar que hay un total de 17 fueros que únicamente figuran en el manuscrito latino de los Fueros de 1247 conservado en el castillo de Perelada, y otros 10 que solo se encuentran en uno o dos manuscritos, pero no de los más antiguos, lo que hace pensar que puede tratarse en ambos casos de redacciones efectuadas en el siglo XV, y por tanto son adiciones o «falsos fueros», que no formaban parte del texto original promulgado por Jaime I en 1247.

Novena. El Vidal Mayor no es un texto legal sino una enciclopedia jurídica, seis veces más extensa que los Fueros de 1247. Tenía una finalidad prácti- 
ca muy concreta, pero en ningún caso era la de sustituir el texto foral recién aprobado, razón por la cual nunca fue sometido a examen por las Cortes de Aragón ni confirmado oficialmente por el rey, aunque como libro de consulta tuvo un enorme éxito durante siglos.

Décima. Los Fueros de 1247 constituyen el único cuerpo legal aprobado por las Cortes celebradas en Huesca y promulgado por el rey Jaime I. Tienen carácter y personalidad propia y ese fue uno de los motivos por los que su redacción original latina se mantuvo intacta a lo largo de los siglos, y así aparece en todos los manuscritos oficiales y en todas las ediciones impresas. Las traducciones romance del texto no tenían valor legal alguno, y solo muy limitado desde el punto de vista histórico, razón por la que en estas páginas casi no se las ha tenido en consideración. En cambio, sí que tienen un enorme interés desde una perspectiva lingüística, si bien esa es otra cuestión sobre la que no es necesario extendernos ahora.

\section{Referencias bibliográficas}

BARrero GArcíA, Ana María (2004), «La difusión del Fuero de Jaca en el Camino de Santiago», El Fuero de Jaca, vol. II: Estudios. Zaragoza, El Justicia de Aragón: 113-160.

CANellas López, Ángel (1972), Colección diplomática del Concejo de Zaragoza. 1. Años 1119-1276. Zaragoza, Universidad, «Cátedra Zaragoza».

Delgado EcheVERría, Jesús (1989), «Vidal Mayor. Un libro de fueros del siglo XIII». En Vidal Mayor. Estudios. Huesca, Diputación Provincial, Instituto de Estudios Altoaragoneses: 43-81.

Delgado ECHEVERríA, Jesús (1997), Los Fueros de Aragón. Zaragoza, Caja de Ahoros de la Inmaculada.

Delgado ECHEVERría, Jesús (2004), «Fueros de Jaca y Fueros de Aragón. Tablas de concordancias». El Fuero de Jaca. Estudios. Zaragoza, El Justicia de Aragón: 163194.

GARCÍA EDO, Vicente (2015), «Concordancias entre el Fuero de Estella de 1164 y los Fueros de Aragón de 1247», Glossae. European Journal of Legal History, 12: 360-380.

GARCÍA EDO. Vicente (2016), «El Fuero de Zaragoza en el siglo XII (Aproximación a su estudio)», Revista de Dret Històric Català [Societat Catalana d'Estudis Jurídics ], 15: 165-197.

GARCÍA EDO, Vicente (2017), «La versión latina del Fuero Extenso de Jaca del siglo XII (Una propuesta de reconstrucción del texto)», Aragón en la Edad Media, 28: 39-66. 
Gargallo Moya, Antonio (1992). Los Fueros de Aragón (según el ms. del Archivo municipal de Miravete de la Sierra (Teruel). Zaragoza, Anubar.

GARCÍA GARCÍA, Antonio (1996), «La compilación de Huesca (1247) y el derecho canónico medieval». Glossae. Revista de Historia del derecho europeo, 8: 27-41.

LACARRA DE Miguel, José M. a, MARTín DUQUE, Ángel J. (1969), Fueros derivados de Jaca. 1. Estella-San Sebastián. Pamplona, Diputación de Navarra.

Laliena Corbera, Carlos (1988). Documentos municipales de Huesca (1100-1350). Huesca, Ayuntamiento.

LALINDE ABADíA, Jesús (1976), Los Fueros de Aragón. Zaragoza, Librería General.

LEDESMA RuBIO, María Luisa (1992) «Las cartas de población aragonesas y su remisión a los fueros locales. La problemática del fuero de Zaragoza», Ius fugit: revista interdisciplinar de estudios histórico-jurídicos, 1: 63-78.

MARTínez DíEZ, Gonzalo (1980) «En torno a los Fueros de Aragón de las Cortes de Huesca de 1247», Anuario de Historia del Derecho Español, 50: 69-92.

Molho, Mauricio (1964), El Fuero de Jaca. Zaragoza, Consejo Superior de Investigaciones Científicas.

Morales Gómez, Juan José y Pedraza García, Manuel José (1986), Fueros de Borja y Zaragoza. Zaragoza, Anubar.

PÉREZ MARTín, Antonio (1999), Los Fueros de Aragón de 1247 (versión romance). Zaragoza, El Justicia de Aragón.

PÉREZ MARTín, Antonio (2010), Los Fueros de Aragón de 1247. La Compilación de Huesca. Edición crítica del texto oficial latino. Zaragoza, El Justicia de Aragón.

RAmos Loscertales, José María (1925), «Textos para el estudio del derecho aragonés en la Edad Media. Recopilación de fueros de Aragón», Anuario de Historia del Derecho Español, 5: 491-523.

RAMOS LOSCERTALES, José María (1928), «Textos para el estudio del derecho aragonés en la Edad Media. Recopilación de fueros de Aragón», Anuario de Historia del Derecho Español, 5: 1928: 389-407.

TILANDER, Gunnar (1937). Los Fueros de Aragón, según el manuscrito 458 de la Biblioteca Nacional de Madrid. Lund, Leges Hispanicae Medii Aevii.

TILANDER, Gunnar (1956). Traducción aragonesa de la obra «in excelsis Dei Thesauris» de Vidal de Canellas. Lund, Leges Hispanicae Medii Aevii.

Ubieto ArtetA, Antonio (1989), «Los precedentes de los Fueros de Aragón». En Vidal Mayor. Estudios. Huesca, Diputación Provincial, Instituto de Estudios Altoaragoneses: 23-41. 